\title{
Descrição de dieta purificada para indução de quadro de desnutrição protéica em ratos*
}

\author{
Márcia Queiroz Latorraca ${ }^{1}$, Cláudio Alexandre Gobatto ${ }^{2}$, Rozinaldo Galdino da Silva ${ }^{3}$, \\ Clarice Yoshico Sibuia ${ }^{4}$, Everardo Magalhães Carneiro ${ }^{4}$, Maria Alice Rostom de Mello ${ }^{4}$
}

\section{RESUMO}

No presente trabalho é descrita a composição de dieta hipoprotéica (6\% de proteína) purificada para indução de quadro de desnutrição em roedores. A referida dieta foi padronizada em laboratório a partir de modificação da AIN-93 (documento do American Institute of Nutrition que estabelece os padrões nutricionais para roedores de laboratório), visando a obtenção de animais desnutridos para estudar as alterações metabólicas decorrentes da desnutrição protéica associada a situações como exercício físico, gestação e diabetes. A dieta em questão contém os seguintes componentes (g/ $\mathrm{kg}$ ): amido de milho (480), caseína (71,5), dextrina de milho (159), sacarose (121), óleo de soja (70), microcelulose (50), mistura mineral AIN-93-G-MX (35), mistura de vitaminas AIN-93-G-VX, (10), L-cistina (1), cloridrato de colina (2,5). Ratos alimentados cronicamente com a dieta apresentaram sinais comumente presentes na desnutrição protéica humana e de animais de laboratório: redução do ganho de peso, hipoproteinemia, hipoalbuminemia, elevação dos ácidos graxos livres séricos e do glicogênio hepático.

Palavras-chave: Dieta purificada hipoprotéica. Desnutrição protéica. Roedores.

\section{ABSTRACT \\ Description of purified diet to induce protein malnutrition in rats}

The present work describes the composition of a purified low-protein diet (6\% protein) formulated to produce protein malnutrition in rodents. The diet utilized in laboratory was based on the AIN-93 (report of the American Institute of Nutrition establishing dietary standards for nutritional stud-

1. Departamento de Nutrição e Dietética, Faculdade de Enfermagem e Nutrição - UFMT, Cuiabá, MT.

2. Departamento de Educação Física, Faculdade de Ciências - Unesp, Bau$\mathrm{ru}, \mathrm{SP}$.

3. Departamento de Educação Física - UFSCar, São Carlos, SP.

4. Departamento de Educação Física, Instituto de Biociências - Unesp, Rio Claro, SP. ies with laboratory rodents), which was modified to investigate in malnourished rats the metabolic alterations induced by protein-deprivation associated to situations as physical exercise, pregnancy and diabetes. This diet has the following composition $(\mathrm{g} / \mathrm{Kg})$ : cornstarch (480), casein $(71,5)$, dextrinized cornstarch (159), sucrose (121), soybean oil (70), microcellulose (50), mineral mix-AIN-93-G-Mx (35), vitamin mix-AIN-93-Vx (10), L-cystine (1), choline chlorhydrate (2,5). Rats fed such diet showed features of malnutrition which have been observed in man and laboratory animals: low weight gain rates, low serum protein and albumin levels, high serum free fatty acids and increase of hepatic glycogen stores.

Key words: Purified low-protein diet. Protein malnutrition. Rodents.

\section{INTRODUÇÃO}

A desnutrição protéico-calórica é importante problema médico-social em países em desenvolvimento. No Brasil, $30,7 \%$ das crianças menores de cinco anos sofrem de alguma forma de desnutrição; na região Sudeste, o percentual é de $21,7^{1}$. As soluções básicas para diminuir a incidência da desnutrição - distribuição de renda e consequiente disponibilidade de alimentos - podem, algum dia, ser alcançadas, mas não se pode garantir que essas medidas, por si sós, corrigirão os casos já instalados. Nesse sentido, torna-se importante o desenvolvimento de pesquisas com a finalidade de entender melhor as alterações orgânicas decorrentes da desnutrição. Talvez seja esse o caminho para chegar a procedimentos mais efetivos para prevenção e tratamento dessa patologia.

Ocorrem diversas adaptações funcionais no desenvolvimento da desnutrição, visando preservar a homeostase de meio interno ${ }^{2}$. Os estudos das alterações que mantêm fenômenos fisiológicos no organismo desnutrido têm contribuído sobremaneira para o estudo de fisiologia, bioquímica e outros ramos das ciências fisiológicas.

Ao longo dos últimos dez anos, procuramos desenvolver, no Laboratório de Biodinâmica, Departamento de Educação Física, IB, Unesp, Rio Claro, modelo experimental, utilizando ratos alimentados com dieta purificada hipoprotéica, para o estudo das adaptações do metabolismo glicídico, em vi- 
gência de desnutrição, a condições como gestação, diabetes e exercício físico. Dados de nossos estudos mostraram que ratas jovens mantidas com dieta hipoprotéica não apresentam a hiperinsulinemia característica da gestação e indicam resposta insulínica deficiente ao estímulo com glicose ${ }^{3,4}$. Seus filhotes são hipoglicêmicos, hipoinsulinêmicos e têm baixo peso ao nascer ${ }^{3}$. Ilhotas isoladas do pâncreas de ratos deficientes em proteína apresentam redução da secreção de insulina e da captação de cálcio frente ao estímulo com glicose ${ }^{5}$. Por outro lado, o pâncreas desses ratos mostra-se parcialmente protegido contra os efeitos diabetogênicos da droga aloxana ${ }^{4}$. Quando submetidos a sessão única de exercício, ratos com desnutrição protéica mostram glicemia e teores musculares de glicogênio baixos, associados a níveis circulantes muito elevados de ácidos graxos livres ${ }^{6,7}$. Após a recuperação nutricional, as alterações do metabolismo glicídico em resposta ao exercício são revertidas ${ }^{8}$.

Dieta purificada hipoprotéica - A dieta purificada utilizada no desenvolvimento dos estudos citados anteriormente foi padronizada no Laboratório de Nutrição e Desenvolvimento do Departamento de Fisiologia e Biofísica do Instituto de Ciências Biomédicas da USP, São Paulo, SP, sob a coordenação da Prof ${ }^{\underline{a}}$ Dr $\stackrel{a}{a}$ Lor Cury, tendo como base a dieta proposta por Moraes e Santos ${ }^{9}$. A dieta hipoprotéica (6\% de proteína) por nós empregada continha a seguinte composição $(\mathrm{g} / \mathrm{kg})$ : caseína (75, valor corrigido para o teor de proteína na caseína), amido de milho (268), glicose (248), sacarose (198), óleo de milho (150), DL-metionina (3), mistura de sais, de acordo com Rogers \& $\operatorname{Harper}^{10}$ (40), mistura de vitaminas, de acordo com Miller et al. ${ }^{11}$ (10) e cloreto de colina (4) ${ }^{3}$. Ratos mantidos cronicamente com essa dieta mostraram características presentes na desnutrição infantil do tipo kwashiorkor $^{2}$ : baixo peso, hipoglicemia, hipoalbuminemia, hipoproteinemia, hipoinsulinemia, elevação dos teores circulantes de ácidos graxos livres e do conteúdo hepático de glicogênio ${ }^{3,5,7,8}$.

Modificações introduzidas na dieta hipoprotéica - A partir do último trimestre do ano de 1994 a dieta AIN-93G, para a alimentação de roedores nas fases de crescimento, gestação e lactação foi adotada no Laboratório de Biodinâmica. Essa formulação, que foi proposta pelo American Institute of Nutrition (AIN) ${ }^{12}$ com o intuito de padronizar dietas-testes para facilitar a interpretação de resultados e garantir a reprodutibilidade destes, tem sido amplamente utilizada em estudos com roedores. Algumas das principais diferenças da formulação AIN-93G, comparada com a dieta anterior, são as seguintes: o teor de gordura é duas vezes menor e o óleo de milho foi substituído por óleo de soja para garantir quantidades adequadas dos ácidos graxos linoléico e linolênico; a principal fonte de carboidrato é o amido de milho, que substituiu parte da sacarose; a glicose foi substituída por dextrina de milho; a quantidade de proteína foi reduzida de $25 \%$ para $17 \%$; L-cistina substituiu DL-metionina como su-

plementação de aminoácidos à caseína, sabidamente deficiente em aminoácidos sulfurados; fibras alimentares $(50 \mathrm{~g} /$ $\mathrm{kg}$ de ração) foram adicionadas à dieta atual; as quantidades de vitaminas e minerais foram alteradas; microelementos como silício, fluoreto, níquel, boro, lítio e vanádio foram acrescentados à mistura de sais.

Dessa forma, houve necessidade de proceder à adaptação da dieta hipoprotéica por nós utilizada para induzir desnutrição. A composição da nova dieta hipoprotéica, elaborada no Laboratório de Biodinâmica, e a formulação da AIN-93G encontram-se descritas na tabela 1 . Na dieta hipoprotéica $(6 \%$ de proteína), a caseína foi substituída por carboidratos, sendo mantidas as proporções de amido, dextrina e sacarose, bem como a de L-cistina em relação ao teor de caseína, e a concentração dos demais componentes.

\section{RESULTADOS}

Para testar a eficácia da nova dieta hipoprotéica purificada descrita na tabela 1, ratas adultas (90 dias) grávidas, da linhagem wistar, foram alimentadas com ela durante a gestação e a lactação (grupo H). Como controles, foram usadas ratas grávidas de mesma idade e linhagem, alimentadas durante a gestação com a ração AIN-93G (grupo N). No início da gravidez, as ratas apresentavam peso corporal médio semelhante $(225 \pm 15 \mathrm{~g}$ para o grupo $\mathrm{N}$ e $214 \pm 15 \mathrm{~g}$ para o grupo $\mathrm{H}$ ). Embora a dieta hipoprotéica não tenha alterado o ganho de peso durante a gestação $(118 \pm 20 \mathrm{~g}$ para o grupo $\mathrm{N}$ e $120 \pm 30 \mathrm{~g}$ para o grupo $\mathrm{H})$, tamanho da ninhada $(9,9 \pm 3,3$ filhotes por ninhada para o grupo $\mathrm{N}$ e 11,3 $\pm 2,1$ para o grupo $\mathrm{H})$, consumo alimentar $(385 \pm 30 \mathrm{~g}$ para o grupo $\mathrm{N}$ e $390 \pm$ $60 \mathrm{~g}$ para o grupo $\mathrm{H})$ e ingestão de energia $(1.458 \pm 110 \mathrm{kcal}$

\section{TABELA 1}

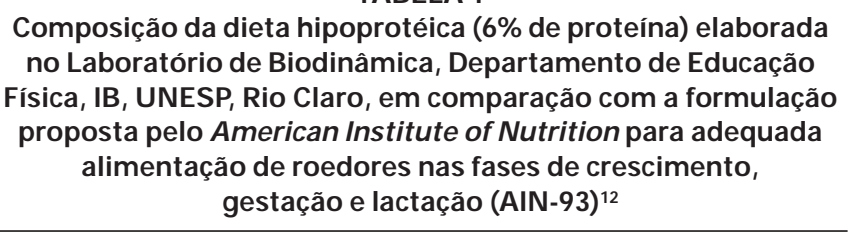

\section{Componentes $(\mathbf{g} / \mathbf{k g})$}

Caseína*

Amido de milho

Dextrina de milho

Sacarose

L-cistina

Óleo de soja

Mistura de sais (AIN-93GMX)2

Mistura de vitaminas (AIN-93GVX)2

Microcelulose

Cloridrato de colina

\section{AIN-93G}

$\begin{array}{cc}202 & 71,5 \\ 397 & 480 \\ 130,5 & 159 \\ 100 & 121 \\ 3 & 1 \\ 70 & 70 \\ 35 & 35 \\ 10 & 10 \\ 50 & 50 \\ 2,5 & 2,5\end{array}$

* Valores corrigidos para o teor de proteína contida na caseína ( $84 \%$ de proteína) e determinada pelo método de Kjeldahl13. 


\section{TABELA 2}

Peso corporal (g), glicose (mg/dL), proteínas totais (g/ dL), albumina $(\mathrm{g} / \mathrm{dL})$ e insulina $(\mathrm{ng} / \mathrm{mL})$ séricas de recém-nascidos de ratas alimentadas durante a gestação com dietas normoprotéica (N) ou hipoprotéica $(\mathrm{H})$

\begin{tabular}{cccccc}
\hline Grupos & $\begin{array}{c}\text { Peso ao } \\
\text { nascer }\end{array}$ & Glicose & $\begin{array}{c}\text { Proteínas } \\
\text { totais }\end{array}$ & Albumina & Insulina \\
$\mathrm{N}$ & $5,5 \pm 0,5$ & $100,0 \pm 35,5$ & $1,9 \pm 0,3$ & $0,8 \pm 0,2$ & $1,5 \pm 0,5$ \\
& $(110)$ & $(16)$ & $(16)$ & $(14)$ & $(11)$ \\
$\mathrm{H}$ & $5,0 \pm 0,5^{*}$ & $74,7 \pm 18,3^{*}$ & $1,8 \pm 18,3$ & $0,8 \pm 0,1$ & $1,3 \pm 0,6$ \\
& $(109)$ & $(14)$ & $(14)$ & $(14)$ & $(7)$ \\
\hline
\end{tabular}

Resultados expressos em média $\pm \mathrm{DP}$, com o número de animais entre parênteses.

* Diferença significativa ( $p<0,05$, teste $t$ ) em relação ao grupo $N$.

para o grupo $\mathrm{N}$ e $1.469 \pm 227 \mathrm{kcal}$ para o grupo $\mathrm{H}$ ), os recémnascidos do grupo $\mathrm{H}$ apresentaram peso corporal médio $11 \%$ menor que o dos pertencentes ao grupo $\mathrm{N}$ (tabela 2). A glicemia foi, também, significativamente mais baixa nos recémnascidos do grupo $\mathrm{H}$ (tabela 2).

Durante a lactação houve aumento progressivo do consumo alimentar das ratas de ambos os grupos $(182 \pm 7 \mathrm{~g}$ e $101 \pm$

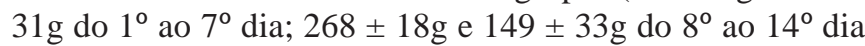
e $366 \pm 12 \mathrm{~g}$ e $204 \pm 22 \mathrm{~g}$ do $15^{\circ}$ ao $21^{\circ} \stackrel{\text { dia }}{ }$ nos grupos $\mathrm{N}$ e $\mathrm{H}$, respectivamente). A ingestão total de energia nos 21 dias de lactação das ratas do grupo $\mathrm{N}(3.074 \pm 95 \mathrm{kcal})$ foi maior do que a das ratas do grupo H $(1.711 \pm 300 \mathrm{kcal})$. Quando corrigidos em função do peso corporal dos animais, o consumo alimentar e a ingestão de energia foram semelhantes para os dois grupos. A restrição protéica durante a lactação resultou em retarde no crescimento da prole. $\mathrm{O}$ ganho de peso total das crias do grupo $\mathrm{H}$ foi, em média, três vezes menor do que o das crias do grupo N. Aos 7 dias de idade, as crias do grupo $\mathrm{H}$ apresentaram peso corporal médio $45 \%$ menor e ao final de 28 dias, quando foram desmamadas, $61 \%$ menor que o das crias do grupo $\mathrm{N}$.

Ao desmame, no estado alimentado, as crias do grupo $\mathrm{H}$ apresentaram concentrações séricas de proteínas totais e de albumina mais baixas do que as do grupo $\mathrm{N}$ (tabela 3), mas não foram notados sinais de edema. Por outro lado, as concentrações séricas de ácidos graxos livres e as hepáticas de glicogênio foram maiores no grupo $\mathrm{H}$ do que no grupo $\mathrm{N}$ (tabela 3). Tais resultados assemelham-se àqueles por nós obtidos em estudos prévios, utilizando a antiga dieta hipoprotéica e consistem em alterações bioquímicas encontradas no kwashiorkor humano ${ }^{2}$. Isso é indicativo de que a nova dieta foi eficaz em induzir quadro de má nutrição nos animais.

Um fato que merece destaque é que animais com desnutrição intra-uterina e pós-natal induzida pela ingestão da antiga dieta hipoprotéica apresentavam, frequientemente, alopecia e lesões cutâneas, sinais que não foram constatados com
TABELA 3

Glicogênio hepático (mg/ 100mg), ácidos graxos livres - AGL $(\mathrm{mEq} / \mathrm{L})$, glicose $(\mathrm{mg} / \mathrm{dL}$, proteínas totais $(\mathrm{g} / \mathrm{dL})$, albumina ( $\mathrm{g} / \mathrm{dL}$ ) e insulina $(\mathrm{ng} / \mathrm{mL}$ ) séricos de crias recém-desmamadas de ratas alimentadas durante a gestação e a lactação com dietas normoprotéica $(\mathrm{N})$ e hipoprotéica $(\mathrm{H})$

\begin{tabular}{ccccccc}
\hline Grupos & $\begin{array}{c}\text { Glicogênio } \\
\text { hepático }\end{array}$ & AGL & Glicose & $\begin{array}{c}\text { Proteínas } \\
\text { totais }\end{array}$ & Albumina & Insulina \\
$\mathrm{N}$ & $7,4 \pm 2,7$ & $0,3 \pm 0,1$ & $127 \pm 22$ & $3,7 \pm 0,53$ & $2,2 \pm 0,5$ & $2,5 \pm 0,9$ \\
& $(43)$ & $(25)$ & $(28)$ & $(28)$ & $(25)$ & $(15)$ \\
$\mathrm{H}$ & $10,0 \pm 3,6$ & $0,6 \pm 0,2^{*}$ & $115 \pm 25$ & $3,1 \pm 0,5^{*}$ & $1,7 \pm 0,3^{*}$ & $0,9 \pm 0,1^{*}$ \\
& $(47)$ & $(33)$ & $(28)$ & $(28)$ & $(27)$ & $(16)$ \\
\hline
\end{tabular}

Resultados expressos em média $\pm \mathrm{DP}$, com o número de animais entre parênteses. * Diferença significativa ( $<<0,05$, teste $t$ ) em relação ao grupo $N$.

o emprego da nova ração. Isso sugere que a nova formulação hipoprotéica é menos agressiva aos animais que a anterior.

Perspectivas de utilização da nova formulação da dieta hipoprotéica purificada em estudos sobre adaptações metabólicas ao exercício na desnutrição - Presentemente, estão em desenvolvimento em nosso laboratório três projetos que visam esclarecer diferentes aspectos das adaptações metabólicas ao exercício em organismos desnutridos. O primeiro tem por objetivo avaliar a interação do metabolismo da glicose e dos ácidos graxos livres em músculos isolados de ratos jovens desnutridos pela ingestão da dieta hipoprotéica aqui descrita após o desmame e, posteriormente, recuperados nutricionalmente através da ingestão da dieta AIN-93G e submetidos a treinamento físico de natação. O segundo visa estudar os efeitos da associação entre desnutrição protéica, obtida através da ingestão da dieta hipoprotéica, e atividade física regular maternas durante a gestação sobre parâmetros bioquímicos no binômio mãe/feto e o terceiro, alterações da função secretória do pâncreas endócrino de ratos jovens com má nutrição causada pela ingestão da dieta dificiente em proteína após o desmame, recuperados nutricionalmente pela posterior administração da dieta AIN-93G e submetidos ao treinamento de natação.

\section{REFERÊNCIAS}

1. Instituto Nacional de Alimentação e Nutrição, Ministério da Saúde (INAN). Pesquisa Nacional sobre Saúde e Nutrição. Brasília, 1990.

2. Waterlow JC, Alleyne GAO. Má nutrição protéica em crianças: evolução dos conhecimentos nos últimos dez anos. São Paulo, SP: Universidade de São Paulo, 1974.

3. Mello MAR, et al. Pregnancy in young rats: effects of malnutrition. Nutr Rep Int 1987;36:527-35.

4. Mello MAR, Luciano E. Effects of protein malnutrition on glucose tolerance in rats with alloxan-induced diabetes. Braz J Med Biol Res 1995; 28:467-70.

5. Carneiro EM, et al. Low protein diet impairs glucose-induced insulin secretion from and ${ }^{45} \mathrm{Ca}$ uptake by pancreatic rat islets. J Nutr Biochem 1995;6:314-8. 
6. Mello MAR. Effects of intrauterine and post natal protein-calorie malnutrition on metabolic adaptations to exercise in young rats. Braz J Med Biol Res 1994;27:2461-6.

7. Neiva CM, Guerino MR, Mello MAR. Análise dos efeitos da desnutrição protéico-calórica sobre as respostas ao exercício agudo (single section) - parâmetros metabólicos. Motriz 1995;1:32-43.

8. Gobatto CA. Alterações metabólicas decorrentes do treinamento físico em ratos previamente desnutridos e recuperados. Dissertação (Mestrado em Ciências Biológicas), Instituto de Biologia, Universidade Estadual de Campinas. Campinas, 1993:132.

9. Moraes e Santos T. The effect of neonatal protein-calorie malnutrition on growth and development of rodent cerebral neurons. PhD Thesis,
Department of Nutrition and Food Sciences, Massachusetts Institute of Technology. Cambridge, 1976:186.

10. Rogers QR, Harper HE. Aminoacid diets and maximal growth in the rat. J Nutr 1965;87:267-73.

11. Miller SA, Dumsza HA, Goldblat SA. Cholesterolemia and cardiovascular sudanophilia in rats fed saline mixtures. J Nutr 1962;77:397-402.

12. American Institute of Nutrition (AIN), AIN-93. Purified diets for laboratory rodents: final report of the American Institute of Nutrition ad hoc writing committee on the reformulation of the AIN-76-A rodent diet. J Nutr 1993;123:1939-51.

13. Albanese AA, Orto LA. Proteins and aminoacids. In: Albanese AA. New methods of nutritional biochemistry. New York: Academic Press, 1963: 84. 